\title{
PARTICIPACIÓN INDÍGENA EN LAS ACTIVIDADES PRODUCTIVAS DEL ESPACIO RURAL DE CÓRDOBA. REVISIÓN DEL PUEBLO DE ENCOMIENDA DEL QUILPO A FINES DEL SIGLO XVI
}

\author{
INDIGENOUS PARTICIPATION IN PRODUCTIVE ACTIVITIES IN RURAL \\ AREAS OF CORDOBA. REVIEW OF THE ENCOMIENDA OF QUILPO \\ AT THE END OF THE XVI CENTURY
}

\author{
Lucas Borrastero*
}

\begin{abstract}
Este trabajo es parte de una investigación mayor donde analizamos las relaciones establecidas entre las sociedades indígenas y el sistema colonial español en la jurisdicción de Córdoba entre 1573 y 1670 y que tiene entre sus objetivos específicos indagar en la producción y organización de unidades productivas rurales pertenecientes a encomenderos y a otros colonos. En este artículo examinaremos una unidad productiva específica: el pueblo de encomienda del Quilpo (ubicado al Noroeste de Córdoba), a partir de la revisión de una Rendición de Cuentas de 1595-1598, ya estudiada por G. Doucet (1986). Articulando este documento con fuentes contemporáneas e investigaciones arqueológicas y etnohistóricas, buscaremos dar cuenta de las características que adquirió la participación indígena en las actividades económicas y en los espacios productivos de una encomienda rural de Córdoba a fines del siglo XVI.
\end{abstract}

Palabras claves: Sociedades indígenas, unidades productivas rurales, historia colonial de Córdoba (Gob. del Tucumán).

This work is part of a larger research where we analyze the relationships established between indigenous societies and the spanish colonial system in the jurisdiction of Córdoba between 1573 and 1670. One of the specific objectives of this research is to investigate the production and organization of rural productive units belonging to encomenderos and other colonists. In this article we will examine a specific productive unit: the encomienda of Quilpo (located in the Northwest of Córdoba), based on the revision of a Rendición de Cuentas of 1595-1598, already studied by G. Doucet (1986). Articulating this document with contemporary sources and archaeological and ethno-historical researches, we will try to give an account of the characteristics acquired by the indigenous participation in the economic activities and in the productive spaces of a rural encomienda in Córdoba at the end of the 16th century.

Key words: Indigenous societies, rural productive units, colonial history of Córdoba (Gob. del Tucumán).

\section{Introducción}

Este trabajo forma parte de una investigación mayor donde analizamos las formas que adoptaron las relaciones establecidas entre las sociedades indígenas y el sistema colonial español en la jurisdicción de Córdoba entre 1573 y 1670, centrándonos en el examen de la participación indígena en el proceso de producción de mercancías (específicamente en el proceso técnico de trabajo) incentivado u organizado por los colonos españoles; para luego reflexionar si dichas actividades deben ser calificadas como parte de un proceso de "hispanización" de las sociedades indígenas o si sus características nos permiten construir otras formas de interpretación.

Uno de los objetivos específicos de esta investigación, consiste en analizar las unidades productivas rurales, encomenderas y de otros colonos (pueblos de indios, chacras, estancias y obrajes) examinando su producción, organización y trabajadores, los instrumentos, técnicas y materias primas utilizadas, ya que entendemos que un examen detallado de estos procesos nos brindará los indicios necesarios para comprender el proceso llamado por ahora de "hispanización"1.

En este artículo abordaremos este objetivo específico, recuperando análisis previos (Borrastero 2015,2018 ) donde, a partir de la revisión de investigaciones respecto del espacio rural de Córdoba ${ }^{2}$, observamos cómo la producción diversificada de las unidades productivas rurales (con ganados, productos agrícolas, etc.) se va especializando hacia finales del siglo XVI en la producción textil, cuando Córdoba se inserta en circuitos comerciales interregionales

* IDH-CONICET y Escuela de Historia, Facultad de Filosofía y Humanidades, Universidad Nacional de Córdoba. Córdoba, Argentina. Correo electrónico: lborrastero@gmail.com 
que unían los mercados de Potosí, Buenos Aires y Brasil y por otro lado, Chile.

El pionero estudio realizado por Doucet (1986), basado en una Rendición de Cuentas por Tutela de 1595-1598, nos permitió aproximarnos a las características que tuvo la producción en un pueblo de encomienda ubicado en el valle de río Quilpo (Noroeste de Córdoba) y observar los múltiples aprovechamientos brindados por una encomienda que se especializaría en la producción de textiles bastos $^{3}$.

En este artículo realizaremos nuestra propia revisión del documento trabajado por Doucet ${ }^{4}$, complementando su análisis con otras fuentes contemporáneas y con investigaciones arqueológicas y etnohistóricas acerca de los grupos indígenas que habitaron el Quilpo durante el período previo y posterior a la conquista española.

\section{Ambiente y recursos de los grupos indígenas del valle del río Quilpo}

Para comprender las características de las sociedades indígenas que habitaban la zona del Quilpo, describiremos en primer lugar los principales aspectos del ambiente y los recursos disponibles en este espacio 5 .

El paisaje serrano de Córdoba se caracteriza por tener una multiplicidad de ambientes, presentando diferentes potenciales según la región y altitud ${ }^{6}$. En el sentido longitudinal se despliegan distintos "pisos ecológicos" existiendo en cada uno diversos recursos animales y vegetales de los que hicieron uso las poblaciones indígenas (Tell 2008: 39-55) ${ }^{7}$.

Si bien no hay referencias exactas del lugar donde pudo estar el llamado pueblo del Quilpo ${ }^{8}$, sabemos que se ubicó en el valle del río Quilpo, el que forma parte del paisaje de los valles Noroccidentales de Córdoba. González Navarro (2012), en un estudio de la población indígena de estos valles, afirma que estos surgen a la altura de Los Gigantes, cuando las Sierras Grandes se dividen hacia el Norte, ramificándose (a manera de los dedos de una mano) en diferentes valles atravesados por cursos de agua. Estos ríos corren con dirección Sureste-Noroeste y derraman en la depresión de las Salinas Grandes, donde el entorno comienza a ser más árido y seco (Figura 1).

Los trabajos arqueológicos revisados señalan que los grupos indígenas que habitaron las Sierras Centrales desde 500 d.C. hasta el período de la conquista española, lograron establecer una forma económica de carácter mixto, que incorporó a la agricultura como una estrategia de subsistencia junto con la caza y la recolección ${ }^{9}$. Este tipo de economía configuró un sistema de asentamiento complejo, integrando espacios residenciales con sitios multipropósitos para la caza, la molienda de granos y la recolección de algarroba, chacras del cultivo, talleres líticos, canteras y fuentes de arcilla. Las poblaciones indígenas se concentraron por lo general en los fondos de valles junto a los terrenos de cultivo y a las fuentes de agua, en ambientes de transición que facilitaban el acceso a variados recursos y disminuían los costos de obtención (Laguens y Bonnin 2009: 175, 254-257).

Según el análisis específico realizado por M. Medina (2008), el valle del río Quilpo se ubica en una zona de transición entre el bosque serrano y el chaqueño, teniendo como rasgo central una alta disponibilidad de agua y presencia de terrenos sedimentarios aptos para el cultivo, afirmando que los grupos que allí habitaban desarrollaron una agricultura de pequeña escala, con cultivo de maíz, zapallo, poroto y probablemente quinua, en los terrenos de fondo del valle y las quebradas laterales.

Los asentamientos indígenas se articularon con los espacios agrícolas y de recolección, concentrados en torno a grandes algarrobales, siendo la "algarroba" un fruto central en la alimentación y base de la aloja y la chicha. Estas bebidas eran consumidas en grandes cantidades durante el período de recolección (diciembre y enero), momento en el que grupos indígenas (ligados familiar o políticamente) realizaban "rituales colectivos" denominados por los españoles juntas y borracheras (Castro Olañeta 2006: 153-175).

Las investigaciones arqueológicas y etnohistóricas señalan también el registro de actividades textiles realizadas por los grupos que habitaban este espacio durante el período previo a la conquista española (Serrano 1945: 74; Piana 1992: 58-59; Tissera 2018) ${ }^{10}$.

\section{Conquista de los pueblos del Norte y Noroeste de Córdoba}

La invasión española a los pueblos indígenas que habitaban el espacio que luego se configuraría como la jurisdicción de Córdoba, formó parte del proceso general de colonización de la gobernación de Tucumán. Los conquistadores españoles, que 


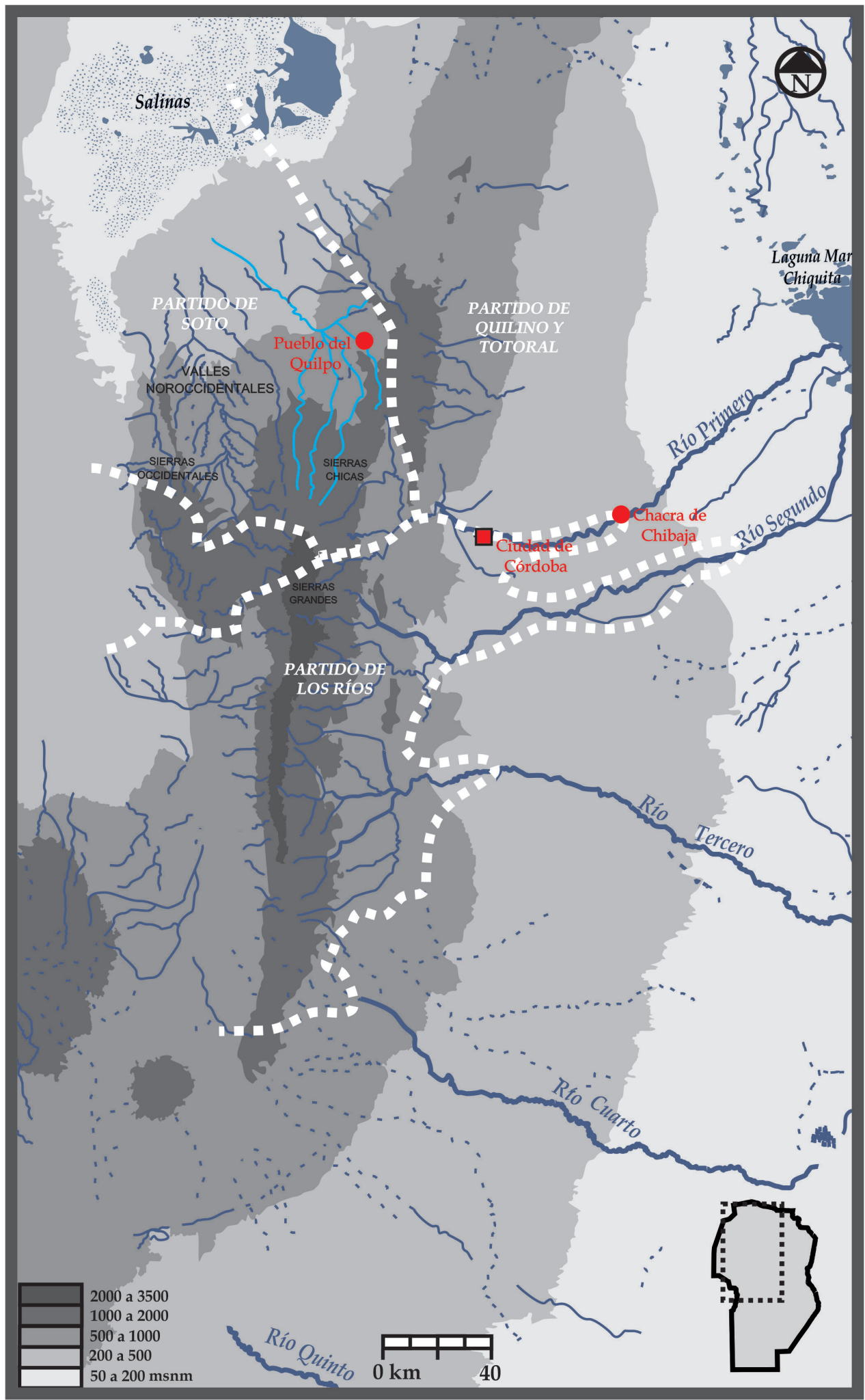

Figura 1. Mapa unidades productivas rurales. 
traían la experiencia de invasión respecto de las complejas sociedades andinas, al establecer relaciones con los indígenas de Córdoba, afirmaban -al igual que de los lules- que eran gente de menos razón y que sus caciques eran menos obedecidos, vinculando esta apreciación con la ausencia del dominio incaico en la región (Palomeque 2000: 98; Taboada y Angiorama et al. 2013).

Los grupos indígenas del Norte y del Noroeste (donde se establecería el pueblo de Quilpo) fueron los primeros en ser visitados y encomendados por los españoles, dando lugar a numerosos pleitos, producto de los límites poco claros fijados en el otorgamiento de las primeras encomiendas y del gran interés suscitado por los indígenas que allí habitaban.

\section{La encomienda del Quilpo}

El registro de la primera cédula de encomienda del Quilpo no se ha encontrado, existiendo referencias contrapuestas en torno a quién fue su primer propietario. A partir de la información brindada por la Rendición de Cuentas analizada y la bibliografía consultada (Montes, 2008: 357; Doucet 1986: 67), sabemos que a fines de 1580 la encomienda estaba en manos de Juan de Soria, pasando luego de su muerte en 1593, a su hijo mayor: Felipe de Soria. Por ser este último menor de edad, entre 1593 y 1595 queda como tutora su madre Catalina de Bustos, quien se casaría con Luis Abreu de Albornoz, encargándose este de la administración hasta 1598. La Rendición de Cuenta corresponde al período en el que Luis de Abreu tuvo a cargo la tutela de la encomienda $(1595-1598)^{11}$.

\section{Familias encomenderas}

Juan de Soria (1547-1593) participó con su familia en la fundación de Córdoba, logrando ser propietario -junto con su hermano Pedro de Soria-de varios solares en el espacio urbano, donde tenían las casas de sus moradas y otras unidades productivas, entre ellas el único molino harinero de la ciudad, donde trabajaban indígenas naturales de quelpo, según pudimos observar en un pleito entre estos encomenderos y el Cabildo de $1588^{12}$. En este pleito se evidencia un fenómeno de mayor alcance (al que nos hemos referido en un trabajo previo, Borrastero 2015) relativo a la "saca" o traslado de familias indígenas procedentes principalmente del Noroeste de Córdoba, por los vecinos, para que trabajaran en los espacios productivos urbanos, asunto que retomaremos al final del artículo (hemos ubicado las propiedades urbanas de la familias analizadas en una cuadrícula elaborada a partir de la información brindada por L. Colombres 1980. Figura 2).

La familia Soria en el espacio rural, además de la encomienda del Quilpo, tenía una chacra en Chibaja sobre el río Primero (Figura 1), dedicada principalmente a la producción agrícola de trigo, maíz y cebada y donde se domaban novillos. Según pudimos observar en la Rendición de Cuentas, la producción en Chibaja se complementaba con la de Quilpo, sirviendo al abastecimiento de la familia y del servicio indígena de la ciudad.

La otra familia española involucrada en la administración del pueblo del Quilpo fue la de Luis de Abreu (nacido en España en 1556/59), quien llega al Tucumán, avecindándose primero en Santiago del Estero y luego en Córdoba, donde se casa con Catalina de Bustos (viuda de Juan de Soria). Este matrimonio le permitió organizar una amplia red de vínculos familiares, debido a ello articularía diversos negocios y actividades productivas.

En el espacio urbano, L. de Abreu tenía un solar con su casa y disponía de unas chacras cercanas, donde obtenía los mantenimientos para la subsistencia de su familia y servicio y para comerciar con otros vecinos. En el espacio rural, poseía encomiendas en la zonas de Ischilin, Olaen y Salsacate (Piana 1992: 207-209), destinadas principalmente a la cría de ganado, base de sus negocios de transporte y fletes, con los que participaría en la compra y venta de esclavos, comercio dinamizado hacia fines del siglo XVI, en el eje Buenos Aires-Potosí, en donde Córdoba se ubicaría en lugar privilegiado como plaza de distribución.

\section{Análisis de las actividades productivas}

La encomienda del Quilpo se ubica en el contexto general de la gobernación de Tucumán, donde -salvo escasas excepciones- la encomienda se caracterizó por la continuidad del sistema de tributación denominado servicios personales. Este sistema fue analizado tempranamente por A.M. Lorandi, quien mostró las particularidades del Tucumán como espacio marginal dentro del virreinato de Perú, donde los controles institucionales resultaron poco efectivos y las desviaciones respecto de las 


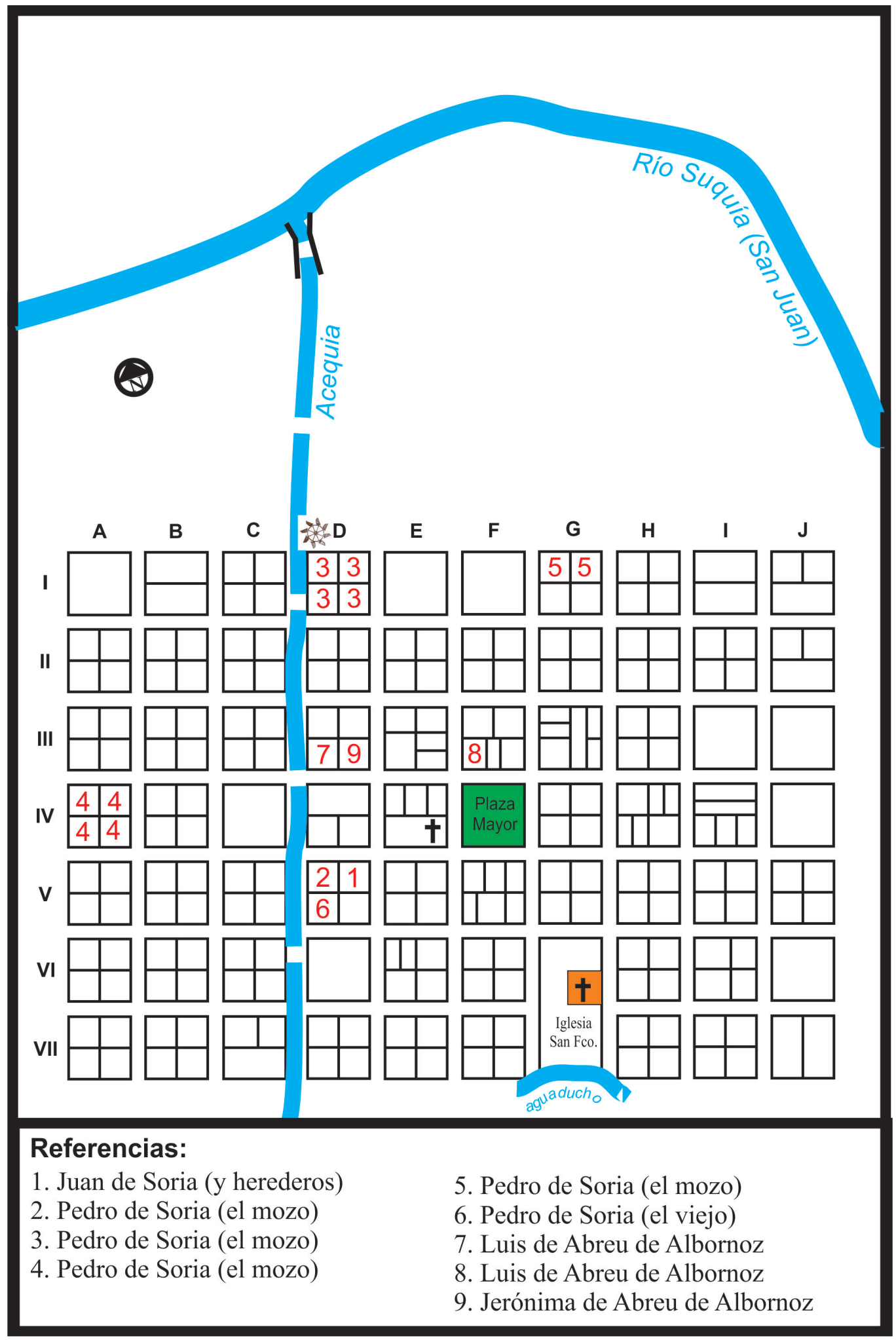

Figura 2. Gráfico basado en la información y croquis sobre la propiedad urbana de Córdoba para el año 1600 de Luque Colombres (1971-1980). 
ordenanzas reales fueron mucho mayores que en las zonas centrales (Lorandi 1988: 140).

Según el análisis realizado por Doucet (1990), las ordenanzas de Abreu (1576) "legalizaron" los servicios personales, siendo "acordadas" con los vecinos encomenderos, quienes en este espacio lograron mantener una forma de explotación directa de los indígenas encomendados (Doucet 1990: 149-150). Estas ordenanzas no fijaron una tasa en producto o dinero, ni separaron al pueblo de indios del encomendero sino que por el contrario autorizaron al encomendero a mantener "sujeta bajo su jurisdicción" a toda la familia indígena en la que se ejerció su dominio según su capacidad de explotación (Palomeque 2000: 114-115). Este tipo de encomiendas les permitió a vecinos como Juan de Soria o Luis de Abreu disponer de trabajadores indígenas, capital inicial para emprender diversas actividades productivas y comerciales.

En su investigación respecto del Quilpo, Doucet describe a una figura central en el funcionamiento de estas encomiendas: los pobleros, administradores de los encomenderos en el espacio rural y en muchos casos especialistas en determinadas actividades productivas. Los pobleros estaban encargados de organizar la producción, enseñarles a los indígenas y realizar todas las tareas necesarias para recaudar el tributo y entregárselo al encomendero. En general se los contrataba por un tiempo corto (en Quilpo hubo 5 pobleros entre 1595 y 1598 . Tabla 1 ) y se les pagaba con un porcentaje de la producción realizada, lo que generaba mayores niveles de explotación a los indígenas (Doucet 1986: 71-77).

El pueblo de Quilpo formó parte del "partido de pueblos de indios de Soto" (Carmignani 2013) visitado por el teniente de naturales Francisco de Avellaneda por órdenes del gobernador Alonso de Ribera en $1607^{13}$ (Figura 1). En el informe del partido de Soto, encontramos una llamativa descripción de los pobleros que trabajan en este espacio:

En algunas partes por no ser los yndios muchos les parece no tener pobleros españoles y tienen yndios yanaconas o yndias que son mas perjudiciales que vn poblero español por malo que sea ya agora [...] porque el yndio o yndia que es poblero açen que trauajen para su aprouechamiento [...] y que les yle lana de la tierra y que agan otras cossas y de noche chicha de algarroua para acer ellos sus juntas y vorracheras y se descalabran y yeren en ellas por no auer español que los desparta [Documento transcripto por Carmignani 2013: 12] [Este subrayado y los subsiguientes son propios].

En esta cita se puede observar que en los pueblos donde los indígenas no eran tan numerosos, como en el caso del Quilpo ${ }^{14}$, los encomenderos no establecieron necesariamente pobleros españoles sino que estos podían ser yndios yanaconas o yndias, quienes al mismo tiempo que se desempeñaban como administradores de los encomenderos, exigían que les hicieran hilados de lana de la tierra, chicha de algarroua y otras cosas para su aprovechamiento y participan en las juntas y borracheras, "rituales colectivos" indígenas realizados en este espacio desde el período previo a la conquista.

Para conocer la producción realizada en el Quilpo, indagamos en el registro de las mitas o tributos "por tandas" entregados por los indígenas encomendados a los pobleros, asentados en la Rendición de Cuenta (Tabla 1). Al igual que Doucet (1986), observamos que la principal producción tributada entre 1595-1598 fue la textil, compuesta mayormente por sayales de lana, lienzos de algodón y costales de cabuya. A su vez, en el registro de las mitas advertimos la importancia de los productos recolectados en el bosque serrano, entre ellos: la brea, la miel y la grana de cochinilla; recursos propios del ambiente utilizado por los indígenas durante el período anterior a la conquista y que durante el período colonial pasaron a formar parte los tributos, producidos bajo nueva lógica y forma de explotación.

\section{Producción textil}

En Quilpo se producían textiles de lana y de algodón, sin embargo, la materia prima no provenía siempre de Córdoba. La producción de textiles de lana se difundió en esta jurisdicción hacia fines del siglo XVI, gracias al rápido abastecimiento de ganado ovino conseguido por los vecinos de esta ciudad. Para realizar los textiles de algodón, en cambio, se debía traer la materia prima de otro lugares como Santiago del Estero o Talavera (Assadourian 1982 [1968]: 25), representando los textiles de algodón de Quilpo, un caso especial en Córdoba.

Uno de los tributos textiles que más creció entre 1595 y 1598 fueron los costales de cabuya, inexistentes en 1595, hacia 1598 representaban 
Tabla 1. Mitas producidas en Quilpo entre 1595 y 1598

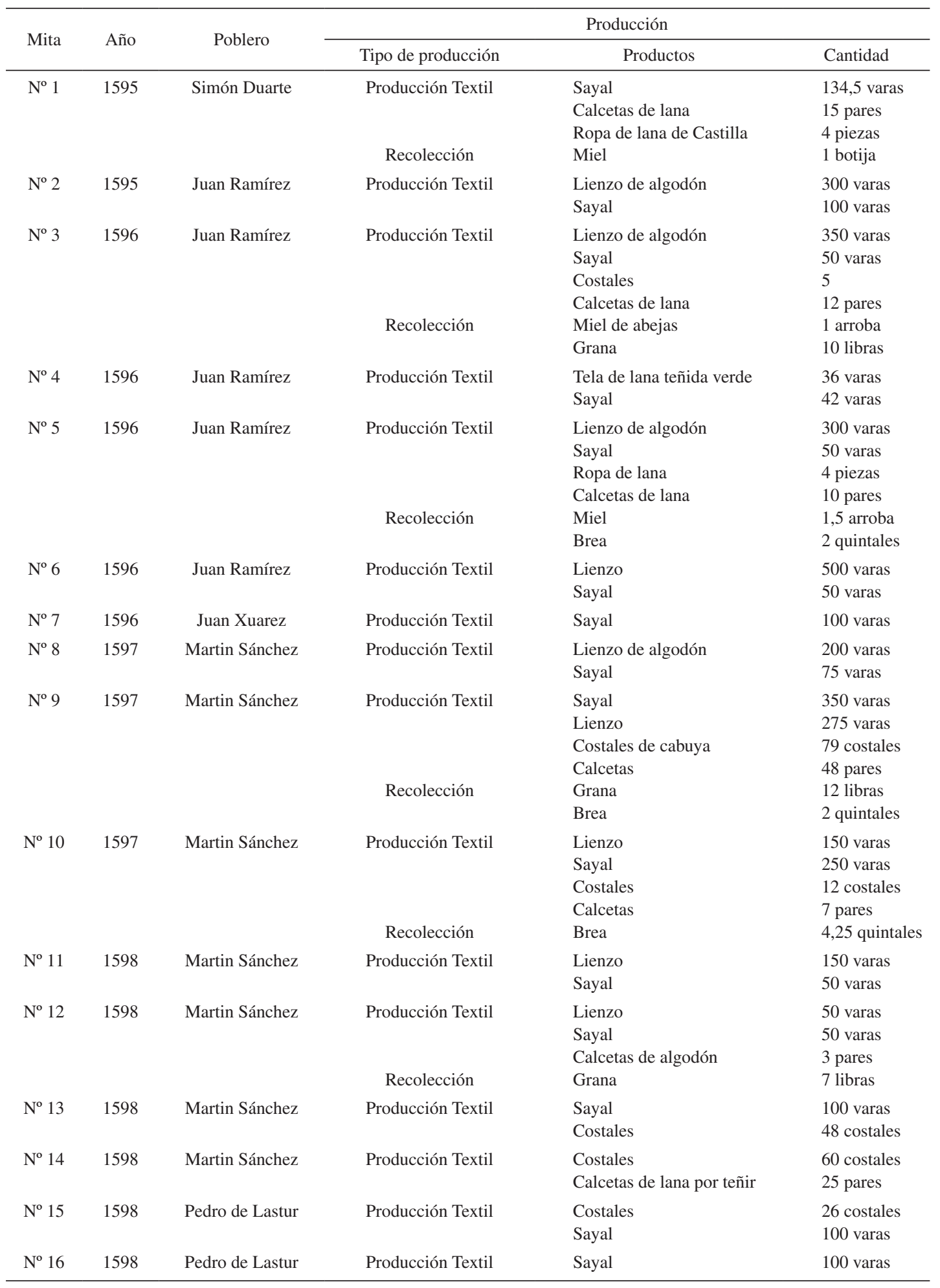


el $32 \%$ del tributo total entregado, superando al lienzo (Tabla 1). Estos costales eran realizados a partir del hilado de la fibra del agave americano, especie vegetal presente en el ambiente chaqueño de Córdoba (llamada chaguar en la documentación colonial), que según las investigaciones arqueológicas fue utilizada por las poblaciones indígenas antes de la conquista, para realizar piezas textiles como bolsas o redes ${ }^{15}$.

A partir de la documentación analizada, consideramos que la producción textil conllevó para los indígenas encomendados la realización principalmente de dos tareas: a) el hilado y b) el tejido.

a) El hilado fue una actividad realizada principalmente por las mujeres indígenas, fenómeno del que hay numerosas referencias en las fuentes coloniales tempranas, que describen no solo las exigencias tributarias sino también los abusos a los que las indígenas eran sometidas (Lorandi 1988, Quiroga 2012, entre otros).

Las visitas ordenadas por el gobernador Alonso de Ribera en las jurisdicciones de varias ciudades del Tucumán entre 1606 y 1607, brindan información interesante acerca de este tema. En los informes de los partidos de Santiago del Estero, Catamarca y Córdoba, pudimos observar que los tenientes de naturales exigían a los encomenderos, en relación con el hilado, que respetaran "lo tasado en las ordenanzas"; que fijaban que a cada india se le entregaran por día (3) tres onzas de algodón (o de lana) para que realizaran (1) una onza de hilado (y no más), debiendo trabajar de lunes a jueves, dejando de viernes a domingos y las fiestas para otras actividades ${ }^{16}$. En estas visitas, si bien los tenientes de naturales debían hacer cumplir las ordenanzas de Abreu (1576), que como señalamos no habían fijado una tasa o cantidad a los tributos, buscaban que se cumpliera una cantidad de hilado según "lo tasado en las ordenanzas". Guiándonos por esta observación ${ }^{17}$, encontramos una carta del gobernador Ramírez de Velazco al rey de 1590, en la que afirmaba lo siguiente:

La tassa que oy tienen es que trabajan quatro dias en la semana en hilar un poco de algodon o lana y daseles cada dia a cada yndia tres onzas de algodon y buelven una de hilado de manera que hecha la quenta de diez meses porque los otros dos se les da para sus sementeras vienen a trabajar quitadas las fiestas ciento y treinta e seis dias [...] este es el tributo de esta tierra porque los yndios fuera de una sementera e hazer una cassa e texer este lienço y hazer algun cordoban e alpargates para sus encomenderos ni sirven de otra cossa y de sacar al tiempo alguna miel conforme a esto vea vuestra magestad lo que fuere servido [Documento transcripto por Carcano 1929 [1590]: 309].

Este fragmento del documento referido a los tributos entregados por indígenas en el Tucumán, menciona una tasa para hilado que debían realizar las mujeres indígenas, similar a la aludida por los tenientes de naturales en sus informes de 1606-1607, es decir: que cada india entregara por día (3) tres onzas de algodón (o lana) para realizar (1) una onza de hilado, de lunes a jueves, durante diez meses al año, restando los días de fiestas.

El establecimiento de una cantidad fija de hilado en el marco de la encomienda de servicios personales, es un fenómeno al que ya se había referido Lorandi (1988), afirmando que los indios de encomienda en el Tucumán no estaban tasados, siendo la única excepción las mujeres que trabajaban en obrajes textiles, de las que había numerosas denuncias en torno a la explotación y abusos realizados, que buscaron ser castigados por las autoridades coloniales (Lorandi, 1988: 148 y $157-158)$.

Este asunto también fue analizado por L. Quiroga (2012) en su trabajo concerniente a San Juan Bautista de la Ribera, donde indagó en la transformación de los hilados realizados por las mujeres (entendidos como partes de un saber tradicional) en bienes obtenidos bajo coacción colonial. Allí, examina los significados de la palabra guarço en la documentación colonial referida a la medida de peso o magnitud de vellón que los encomenderos entregaban a las indígenas para que hilaran. Al respecto, cita la relación del padre Juan Ximénez $(1607)^{18}$, quien afirmaba que los pobleros les repartían y pesaban a las indias tres onzas de algodón y de lana para que lo hilen, es decir, la misma cantidad que encontramos los documentos mencionados previamente. Respecto de este asunto, la autora sostiene que durante la etapa en la que 
estuvieron vigente las ordenanzas de Abreu, en la práctica existió una forma de tributación que combinó el tributo en energía o trabajo, con el tributo medido en cantidad de bienes producidos, como observamos aquí para el caso específico del hilado.

En el informe del partido de Soto, los tenientes de naturales denunciaban que los encomenderos daban por día a cada india (4) cuatro o (5) cinco onzas de lana (o de algodón) para que realizaran (1) una onza de hilado y que además, ayudadas de sus maridos, debían hacer por semana el torcido (hilado) de (2) dos libras de chaguar ${ }^{19}$. La importancia del hilado del chaguar puede constatarse en caso del Quilpo, con el notable crecimiento de los costales de cabuya tributados.

$\mathrm{Al}$ igual que propone Quiroga, entendemos que los hilados (o torcidos en el caso del chaguar) formaban parte de un saber indígena (como sugieren los indicadores arqueológicos) que durante el período colonial pasaron a ser bienes producidos bajo una nueva lógica de producción y condiciones de explotación. A su vez, consideramos que los excesos producidos en los trabajos exigidos, en este caso a las mujeres indígenas, generó que las autoridades fijaran la cantidad de hilado que podía ser exigida, representando un límite, al menos normativo, a la explotación permitida en el marco de los servicios personales.

b) En relación con el tejido observamos que desde el período en el que Juan de Soria era encomendero (fines de 1580), en el pueblo de Quilpo había registro de telares, peines y otras herramientas propias de la producción textil en telar, instrumentos que según las referencias documentales indirectas, estaban en un espacio obrajero, controlado por el poblero.

Los tejidos en telar fueron realizados principalmente por los varones indígenas, denominados en la Rendición de Cuentas telacamayos para diferenciarlos de los indígenas pastores. Los principales textiles producidos en Quilpo fueron los sayales de lana y los lienzos de algodón, utilizándose los primeros para vestir a los indios de servicio, pagarles a los tejedores y pastores y como "moneda de la tierra", entre otros usos; y los segundos destinados a la confección de piezas textiles para el sector español (camisas, jubones, forro de vestidos, entre otros) o para ser vendidos. Si bien estos tejidos, junto con las calcetas y a la ropa de lana, fueron elaborados en Quilpo, la "terminación" de los textiles destinados al consumo español fue en general realizada en las unidades productivas urbanas, donde la producción estaba controlada de forma más directa por los españoles ${ }^{20}$.

\section{Producción agrícola y ganadera}

Si bien la encomienda de Quilpo fue especializándose en la actividad textil, las producciones agrícolas y ganaderas se mantuvieron durante todo este período, siendo consumidas tanto por el sector español como por el indígena.

En la Rendición de Cuentas observamos que en la chacra de Chibaja y en el pueblo del Quilpo se cultivó trigo, maíz y cebada, utilizándose tanto a varones como a mujeres indígenas en los períodos de cosecha. Según Doucet, el trigo estaba destinado principalmente al consumo español y el maíz al consumo indígena. La producción agrícola también se utilizó para pagar el diezmo al poblero y alimentar al servicio indígena del espacio urbano. Aquí se puede observar la complementariedad existente entre las unidades productivas de las que disponían los encomenderos en el espacio urbano y rural de Córdoba, sirviendo tanto para su abastecimiento como para llevar a cabo diferentes actividades productivas y comerciales.

En relación con la producción agrícola, en la siguiente cita observamos que los indígenas encomendados tendrían sus propias chacras de cultivo:

e mandado que la gente no hagan nada este mes de dizienbre por que no tienen comyda por ser fin de año y por que acudan a cojer el trigo y a sus chacaras [...] [hay una] carreta biexa que llevaron el año pasado al pueblo de Quilpo del dicho menor para enserrar la comida y algarroba de los yndios [Transcripto por el autor. Rendición de Cuentas 1598, f.55 v, 62 v.]

El fragmento menciona que los indígenas del Quilpo tenían sus propios espacios agrícolas, a los que iban a fin de año, es decir, en un lugar diferente de donde realizaban los trabajos destinados al tributo. A su vez, evidencia que los alimentos cultivados seguían siendo complementados (como antes de la conquista) con la algarroba, recolectada durante el período estival, momento en el que se realizaban la aloja y las juntas y borracheras, "rituales colectivos" que como observamos continuaron teniendo lugar durante el período colonial. 
El ganado existente en Quilpo se componía de vacas, bueyes, novillos, yeguas, caballos, ovejas y cabras. Para 1598 había 28 bueyes domados, 632 vacas, 93 yeguas domadas, 5 caballos, 236 ovejas, 178 cabras, siendo cada género de ganado utilizado para diferentes actividades productivas, por ejemplo, bueyes y novillos se utilizaban para la actividad agrícola, alimento y transporte, el ganado ovino para las actividades textiles, etcétera.

El cuidado del ganado estaba a cargo de los indígenas pastores, quienes cuidaban los animales del encomendero (y los de otros vecinos) y tenían su propio ganado. Esto se puede observar en el documento, donde menciona que en 1598 había: seysientas y treynta y dos bacas chicas y grandes en que entran [...]las de los yndios (Rendición de Cuentas 1598, f. 60 r). Según Doucet, las vacas de los indígenas y las del encomendero estaban diferenciadas, teniendo cada una "su señal” (Doucet 1986: 93).

Para reflexionar respecto de los espacios configurados por las actividades productivas del Quilpo, compararemos brevemente este caso con la detallada investigación realizada por J.P. Ferreiro (1997) acerca de la encomienda de Maquijata (Santiago del Estero).

Este autor, partir de un expediente judicial (que integraba las cuentas y la administración, similar al del Quilpo), indagó en el funcionamiento de una encomienda particular entre 1600 y 1604, centrándose en su estructura productiva, evidenciando la especialización en la producción textil de la misma (principalmente de lienzo de algodón) en el marco de los servicios personales. Dentro de su investigación, Ferreiro realizó una comparación entre el caso de Maquijata y del Quilpo, basándose en el análisis realizado por Doucet (1986), señalando las similitudes y diferencias entre un caso y el otro (Ferreiro 1997: 122-126), comparación que aquí recuperaremos brevemente.

Una de las diferencias entre estos casos, es que en Maquijata los indígenas encomendados eran alimentados con una producción que procedía desde fuera del repartimiento, debido a ciertos fenómenos que impedían la subsistencia mediante cosechas propias. A su vez, el autor afirma que en Maquijata la presencia de ganados fue menor que en Quilpo y que formaban parte de los bienes exclusivos del encomendero (o sus administradores). Finalmente, en relación con este tema, señala que los indígenas encomendados en Maquijata no residían en la "reducción” sino que acudía allí “por veces" (por turno de mita), localizándose de forma permanente en las Sierras de Guayamba (parte del Alto Ancasti, Catamarca) (Ferreiro, 1997: 95-96).

Estas características señaladas para Maquijata, evidencian una configuración de los espacios productivos diferente a la que observamos en el Quilpo. A partir de la documentación y bibliografía aquí analizada, observamos que los indígenas encomendados en el valle del río Quilpo, continuaron viviendo hacia fines del siglo XVI en el mismo ambiente que habitaban antes de ser encomendados, terrenos en los que tenían sus espacios agrícolas y de recolección, y de donde obtenían recursos, algunos de estos pasaron a formar parte de los productos tributados. Es decir, si bien consideramos que en el pueblo del Quilpo existieron espacios diferenciados y controlados por el poblero, donde se realizaban los tejidos en telar, se producían los cultivos y se cuidaban los ganados del encomendero, el resto de las actividades tuvieron lugar en el mismo ambiente habitado por los indígenas desde el período previo a la conquista, reconfigurados a partir de las nuevas formas de explotación y producción establecida con el dominio colonial.

\section{Reflexiones finales}

Recuperando lo expuesto hasta aquí, realizaremos algunas reflexiones en torno a la participación indígena en las actividades y espacios productivos configurados en la encomienda del Quilpo hacia fines del siglo XVI.

Según observamos, el valle del río Quilpo estaba habitado desde el período prehispánico tardío por grupos indígenas que desarrollaron una economía mixta, que combinaba prácticas agrícolas con la caza y la recolección. Estos grupos fueron tempranamente encomendados y sometidos al sistema de servicios personales, que les permitió a vecinos encomenderos como Juan de Soria y Luis de Abreu, disponer de mano de obra y establecer diferentes unidades productivas, a partir de estas lograron sustentarse e insertarse con su producción en un amplio espacio económico.

Los indígenas encomendados en Quilpo tributaron en mitas a los pobleros, administradores contratados por los encomenderos, que podían ser tanto españoles como indios o indias yanaconas y que según muestran los informes del teniente de naturales de Soto (1607), a la par que organizaban la producción del tributo, tomando para sí parte de 
los aprovechamientos, participaban en "rituales colectivos" indígenas, denominados por los españoles juntas y borracheras.

La principal producción de esta encomienda fue la textil, así como había señalado previamente Doucet, e implicó para los indígenas la realización de dos trabajos principales: el hilado, a cargo de las mujeres (con la excepción del torcido del chaguar donde podían colaborar sus maridos) y el tejido en telar, a cargo de los varones indígenas. En relación con los hilados, destacamos esta habilidad o saber que los indígenas de este espacio tenían antes de la conquista y posteriormente observamos la importante cantidad de hilado de lana (o algodón) y chaguar exigida a las mujeres indígenas encomendadas del partido de Soto. Al respecto, evidenciamos la existencia de una tasa o cantidad fija de hilado establecida por las autoridades, entendiendo a esta medida como un freno o límite normativo a la explotación realizada a las mujeres indígenas que trabajaban en la producción textil, en el marco de la encomienda de servicios personales.

En relación con la configuración de los espacios productivos, para el caso del Quilpo consideramos que, a diferencia de la encomienda de Maquijata, si bien existieron espacios diferenciados y controlados por el poblero (donde se realizaban los tejidos, se producían los cultivos y cuidaban ganados del encomendero), el resto de las actividades indígenas continuaron desarrollándose en el ambiente habitado por los grupos indígenas durante el período previo a la conquista española, en los que tenían sus espacios agrícolas, de recolección y en donde obtenían otros recursos, algunos de estos pasaron a formar parte de los tributos coloniales.

Finalmente y recuperando trabajos previos (Borrastero 2015 y 2018), entendemos que las formas de participación en la producción de los indígenas del Quilpo fueron diferentes a las de las familias indígenas del Noroeste de Córdoba, trasladadas por los españoles para que trabajaran en las unidades productivas urbanas. Estas familias indígenas trasladadas a la ciudad, a diferencia de quienes permanecieron en la zona del Quipo, dejaron de habitar y acceder a los recursos del ambiente en el que estaban al momento de la conquista, y no hay registro de que tuvieran en la ciudad sus espacios agrícolas o ganados ni que continuaran realizando sus "rituales colectivos", sino que pasaron a formar parte de un espacio social más condicionado por el modo de vida y el control del grupo español.

\section{Agradecimientos}

Agradezco los comentarios realizados a la ponencia presentada en la mesa "Tukma: Paisajes, textos, imágenes y materialidades (siglos XVIXVIII)", en especial a Carlos Crouzeilles. También agradezco la lectura atenta de este trabajo a Estela Noli y a los evaluadores anónimos.

\section{Referencias Citadas}

Assadourian, C. S.

1982 [1968] Economías regionales y mercado interno colonial: el caso de Córdoba en los siglos XVI y XVII. En El Sistema de la Economía Colonial. Mercado Interno, Regiones y Espacio Económico, pp. 18-55. Instituto de Estudios Peruanos, Lima.

Borrastero, L.

2015 Las sociedades y su incorporación al proceso de producción de textiles en el período colonial temprano (Córdoba, 1573-1620). Estudios del ISHIR, 5: 54-41.

Borrastero, L.

2018 Las sociedades indígenas y su participación en la economía mercantil durante el período colonial temprano. ¿Un proceso de 'hispanización'? (Córdoba 1573-1620) Revista Síntesis. Artículos Basados en Tesinas de Grado, 7: 326-337.

Carcano, R. J.

1929 Primeras Luchas Entre la Iglesia y el Estado en la Gobernación del Tucumán. Siglo XVI. W.M. Jackson editores, Buenos Aires.
Carmignani, L. D.

2013 Las visitas de los tenientes de naturales a los partidos de pueblos de indios de la Gobernación del Tucumán (1606-1607) Corpus. Archivos virtuales de la alteridad Americana, 3.2.

Castro Olañeta, I.

2006 Transformaciones y Continuidades de Sociedades Indígenas en el Sistema Colonial. El Pueblo de Indios de Quilino a Principios del Siglo XVII. Alción Editora, Córdoba.

Covarrubias, H. S.

[1611] Tesoro de la Lengua Castellana o Española. Luis Sánchez Impresión, Madrid.

Doucet, G. G.

1986 Los réditos de Quilpo: funcionamiento de una encomienda cordobesa a fines del siglo XVI. Jahrbuch für Geschichte Lateinamerikas, 23: 63-119, Colonia.

Doucet, G.G.

1990 La encomienda de servicio personal en el Tucumán, bajo régimen legal: comentarios a las Ordenanzas de Gonzalo de Abreu en Abelardo Levaggi, coord.: El Aborígen y el 
Derecho en el Pasado y el Presente, 141-244, Buenos Aires: Universidad del Museo Social Argentino.

Faberman, J. y Ratto, S. (Coord.)

2009 Historias Mestizas en el Tucumán colonial y en las pampas (siglos XVII y XIX). Editorial Biblos. Buenos Aires.

Ferreiro, J. P.

1997 "Maquijata. Encomienda, tributos y sociedad en el Tucumán colonial temprano", en LORANDI, Ana María El Tucumán colonial y Charcas, Vol. 2, FFyL-UBA, Buenos Aires.

González Navarro, C.

2005 Construcción social del espacio en las sierras y planicies cordobesas (1573-1673). Tesis de Doctorado en Historia Inédita, FFyH-UNCórdoba.

González Navarro, C.

2012 Una aproximación al territorio indígena prehispánico. Córdoba (Siglo XVI). Revista Andes, 23.

Laguens A. y Bonnin M.

2009 Sociedades Indígenas de las Sierras Centrales. Arqueología de Córdoba y San Luís. Editorial UNCórdoba, Córdoba.

Lorandi, A. M.

1988 El servicio personal como agente de desestructuración del Tucumán colonial, Revista Andina. 6: 135-173. Cuzco.

Luque Colombres, C.

1980 Orígenes Históricos de la Propiedad Urbana en Córdoba (Siglos XVI y XVII). Dirección General de Publicaciones UNC, Córdoba.

Medina, $\mathrm{M}$.

2008 Diversificación económica y uso del espacio en el tardío prehispánico del Norte del Valle de Punilla, Pampa de Olahen y Llanura Noroccidental (Córdoba, Argentina). Tesis de Doctorado en Arqueología Inedita, FFyL-UBA, Buenos Aires.

Montes, A.

2008 Indígenas y Conquistadores de Córdoba. Ediciones Isquitipe, Buenos Aires.
Noli, E.

2009 "Mestizajes, identidad y oficio: San Miguel del Tucumán, siglo XVII". En Faberman, J. y Ratto, S. (Coord.) Historias Mestizas en el Tucumán colonial y en las pampas (siglos XVII y XIX). Editorial Biblos, Buenos Aires, 49-78.

Faberman, J. y Ratto, S. (Coord.)

2009 Historias Mestizas en el Tucumán colonial y en las pampas (siglos XVII y XIX). pp. 49-78. Editorial Biblos. Buenos Aires.

Palomeque, S.

2000 El mundo indígena. Siglos XVI-XVIII. En Nueva Historia Argentina. Tomo 2: La Sociedad Colonial, editado por E. Tandeter, pp. 87-114. Editorial Sudamericana, Buenos Aires.

Piana, J.

1992 Los indígenas de Córdoba bajo el régimen colonial (1570-1620). Dirección General de Publicaciones UNC, Córdoba.

Quiroga, L.

2012 Las granjerías de la tierra: actores y escenarios del conflicto colonial en el valle de Londres (Gobernación del Tucumán, 1607-1611) Surandino Monográfico, segunda sección del Prohal Monográfico, II, Buenos Aires.

Santillán Vélez, L.

1882 Actas Capitulares de Córdoba. Libro II [1588-1597]. Municipalidad de Córdoba. Establecimiento tipográfico "Eco de Córdoba".

Serrano, A.

1945 Los Comechingones. Instituto de Arqueología, Lingüística y Folklore de la UNC, Córdoba.

Tell, S.

2008 Córdoba Rural. Una Sociedad Campesina (1750-1850). Prometeo Libros, Buenos Aires.

Tissera, L.

2018 Una aproximación a los estudios tecnológicos de los torteros indígenas de las sierras de Córdoba (Argentina) Anuario de Rosario, 10: 71-91.

\section{Notas}

1 Entendemos por hispanización al proceso, forzado o voluntario, de integración de las sociedades indígenas al sistema colonial, sin que esto implique la recepción de elementos externos, ya que partimos de la idea de que los grupos indígenas fueron actores creativos dentro de este proceso.

La importancia otorgada a la producción y a los trabajos realizados por indígenas y españoles para comprender el proceso de hispanización, se alinea con la perspectiva utilizada por E. Noli (2009) en sus investigaciones sobre los procesos de mestizaje entre las sociedades indígenas y los grupos hispano-criollos de Tucumán durante el período colonial temprano. Esta autora entiende a los trabajos como puentes entre las identidades étnicas prehispánicas y las coloniales, afirmando que mediante "el aprendizaje de técnicas y destrezas producidas en una cultura diferente, trasmitieron una visión de mundo codificada que aceleró cambios identitarios". Así "sin dejar de lado el sentido de la imposición, el trabajo configuró una puerta para procesos de comunicación y comprensión bidireccionales (...) promoviendo procesos de estratificación hacia el interior de los grupos americanos, ladinización, y de indianización de los descendientes europeos" (Noli, 2009: 50-51).

Farberman y Ratto (2009) realizaron una valiosa síntesis acerca de las diferentes perspectivas que han abordado las relaciones entre indígenas y españoles y las variadas identidades configuradas en la gobernación del Tucumán durante el período colonial.

2 Las principales investigaciones revisadas fueron un estudio general de Assadourian (1982 [1968]) respecto de la producción durante el período colonial temprano y tres análisis de caso referidos a distintos pueblos de encomienda de Córdoba: el de Quilpo estudiado por Doucet (1986), el de Quilino analizado por Castro Olañeta (2006) y la investigación de varios pueblos establecidos en las márgenes de los ríos Primero y Segundo realizada por González Navarro (2005).

A lo largo del artículo diferenciamos de manera analítica el espacio urbano y rural de Córdoba, ya que consideramos que las relaciones establecidas entre las sociedades 
indígenas y los grupos españoles fueron "divergentes" en las unidades productivas de un espacio y el otro. A pesar de esto sabemos las importantes continuidades y similitudes que existieron entre ambos espacios, en el paisaje colonial de fines del siglo XVI.

3 RAE NTLLE. Covarrubias (1611) Basta (o Basto) "Significa algunas vezes, la cosa grossera y tosca, sin ningún arte, ni policía".

$4 \quad$ La Rendición de Cuentas analizada se encuentra en el Archivo Histórico de la provincia de Córdoba: Esc. 1, Leg 11, Exp 2, fol 47-80. Esta Rendición se inserta en un expediente judicial de 273 folios, iniciado por el Lic. Antonio Rosillo (protector de bienes menores), solicitando la rendición de cuenta de la encomienda del Quilpo entre 1595 y1598. Doucet realizó el primer análisis específico de este documento, que ya había sido referenciado por Assadourian (1982 [1968] 26-27).

5 Para este análisis recuperamos los trabajos arqueológicos de Laguens y Bonnin (2009), Medina (2008) y los trabajos históricos y etnohistóricos de Montes (2008), Piana (1992), Castro Olañeta (2006), Tell (2008) y González Navarro (2012).

$6 \quad$ El territorio de Córdoba puede ser visto globalmente como una amplia planicie con dos grandes depósitos de agua al Norte (las Salinas Grandes al Oeste y la Laguna de Mar Chiquita al Este), atravesada al Oeste por un extenso cordón serrano con dirección Norte a Sur, denominado Sierras de Córdoba. Estas componen tres cordones principales: las Sierras Chicas, las Sierras Grandes y las Sierras Occidentales.

7 Las características de los "pisos ecológicos" de la sierras, piedemonte y planicies de Córdoba se encuentran desarrolladas en S. Tell 2008: 39-55.

8 Los únicos datos acerca de la ubicación del pueblo de Quilpo fueron brindados por Montes, localizándolo en zona de los "quiscales", región que corría desde el sur del actual San Marcos Sierras hasta Cuchi Corral: el abrupto y boscoso valle por donde corre el río Pinto, que al Norte se llama río de Quilpo (Montes 2008: 357, 444-445).

9 Laguens y Bonnin afirman que las prácticas agrícolas se complementaron con la recolección y la caza, pero fueron preponderantes en la composición de la dieta de las poblaciones indígenas durante el período previo a la conquista española (2009: 383).

10 Dentro de los indicadores arqueológicos indirectos de la actividad textil (cerámica con improntas textiles, agujas de hueso, etc.) se destacan los torteros (utilizados como contrapeso en tareas de hilado), analizados recientemente para Córdoba por Tissera, 2018.

11 Luego, la encomienda pasaría a Felipe de Soria, quien en 1605 haría dejación de la misma, con nueve caciques reducidos en Quilpo, siendo su nuevo encomendero P. Arballo de Bustamante, sobrino de Luis de Abreu (Doucet, 1986: 68).

12 Actas Capitulares de mayo de 1588 en Santillán Vélez, 1882: 26 a 31.

13 Para Córdoba el gobernador Ribera estableció tres "partidos de pueblos de indios": el de los ríos de la ciudad, el de Quilino y el de Soto. Estos correspondían a una jurisdicción menor, dependiente y parte de la jurisdicción de las ciudades, abarcando la territorialidad indígena (incluía pueblos de encomienda y empresas y estancias españolas en donde trabajaba la población encomendada). (Carmignani 2013).

14 Los datos brindados por la Rendición de Cuentas señalan que en Quilpo entre 1595 y 1597 había aproximadamente 100 indios de doctrina (varones mayores de 14 o 15 años), esto permite pensar que en la encomienda había al menos 200 indígenas.

15 Las investigaciones arqueológicas señalan la presencia de indicadores textiles indirectos, que evidencian que estas fibras y otras fueron utilizadas por los grupos indígenas para realizar bolsas o redes (Laguens y Bonnin 2009: 228).

16 Información de las visitas a los partidos de los ríos Dulce y Salado (Santiago del Estero), del valle de Londres (Catamarca) y de los ríos de la ciudad, Quilino y Totoral y Soto (Córdoba). En Carmignani 2013.

17 Agradezco a Lic. Crouzeilles por haberme advertido y facilitado este documento.

18 La relación del padre J. Ximénez fue enviada por el gobernador Ribera al rey junto con informes de los tenientes de naturales aquí analizados, como parte de su denuncia a los excesos cometidos por los encomenderos y pobleros en el Tucumán.

19 El informe del partido de Soto afirma que: las ordenanças no limita que cada yndio a de des chauar torcida [...] dando dos libras de chauar que no puede ser sin gran trauajo del yndio y de su muger la qual a de ylar su guarco de por si se la reparten en esta manera lunes martes miercoles y juebes por la mañana vna libra y lo que queda de juebes viernes sauado y domingo otra. Carmignani 2013: 12.

20 En la Rendición de Cuentas se observa que el encomendero paga a especialistas textiles, dedicados a la confección de ropas y accesorios destinados al sector español, ubicados en el espacio urbano (Rendición de Cuentas, 1598, f. 57v). 